Hydraulic Engineering Repository

Ein Service der Bundesanstalt für Wasserbau

Kadota, Akihiro; Suzuki, Koichi

Local Scour and Development of Sand Wave around T-type and L-type Groynes

Verfügbar unter / Available at:

https://hdl.handle.net/20.500.11970/100280

Vorgeschlagene Zitierweise / Suggested citation:

Kadota, Akihiro; Suzuki, Koichi (2010): Local Scour and Development of Sand Wave around T-type and L-type Groynes. In: Burns, Susan E.; Bhatia, Shobha K.; Avila, Catherine M. C.; Hunt, Beatrice E. (Hg.): Proceedings 5th International Conference on Scour and Erosion (ICSE-5), November 7-10, 2010, San Francisco, USA. Reston, Va.: American Society of Civil Engineers. S. 707-714. 


\title{
Local Scour and Development of Sand Wave around T-type and L-type Groynes
}

\author{
A. $\operatorname{Kadota}^{1}$ and K. Suzuki ${ }^{1}$
}

${ }^{1}$ Hydralic Engineering Laboratory, Department of Civil \& Environmental

Engineering, Faculty of Engineering, Ehime University, 3 Bunkyo-cho, Matsuyama, Ehime 790-8577, Japan; PH +81-89-927-8579; FAX +81-89-927-9831;

email: akado@dpc.ehime-u.ac.jp

\section{ABSTRACT}

There are several types of groyne such as T-type and L-type groynes. These groynes have been empirically constructed worldwide according to several environments. Because the sand transported from the groynes largely affects on the formation of sand wave, the morphological phenomena should be considered systematically and in detail. In this study, the characteristics on changes of bed configuration due to $\mathrm{T}$ and L-type groynes are experimentally revealed comparing with the experimental results of I-type groynes.

Experiments were conducted in a straight flume with a sand box to make a movable bed. To cover a large measurement area at the downstream of groyne, a long-range laser displacement sensor was used. The bed configurations are accurately measured by the measuring system. Experimental results show that the maximum scour depth changes greatly with the groyne types. The difference of bed form downstream of the groyne is seen in development and sand waves.

\section{INTRODUCTION}

Groynes have been used for the stabilization of banks, creating a navigation channel by confining the cross-sectional area and improving habitat of flora and fauna, especially for large rivers worldwide. The most important phenomena are local flow and local scour around the groyne tip. Therefore, sediment transport and its related erosion (or scour) phenomena around the groynes have been studied experimentally and numerically in rivers and coastal regions (The earlier studies by Garde et al. 1961, Gill 1972, Kuhnle et al. 2002). The former studies focused mainly on local scour phenomena around strait (I-type) groynes. There are several types of groyne such as T-type and L-type groynes which have been empirically constructed worldwide according to several environments in rivers. However, a little information is obtained on changes of bed configuration as well as local scour around the different shaped groynes. Because the sand transported from the groynes largely affects on the formation of sand wave far downstream area, these phenomena should be also considered systematically and in detail. 


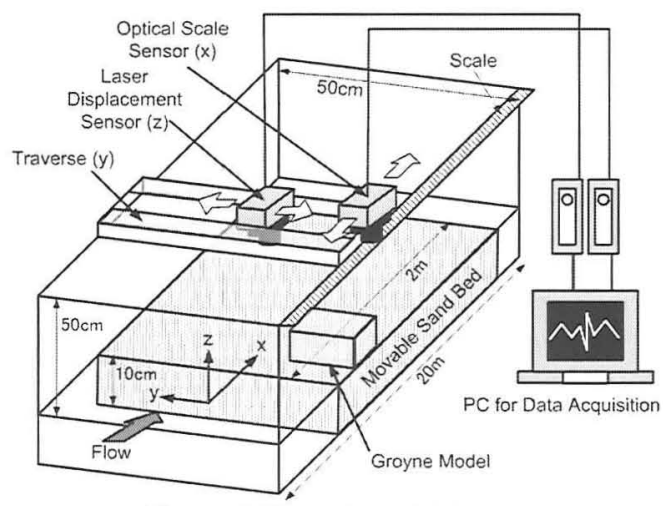

Figure 1 Experimental Setup

In this study, the characteristics on changes of bed configuration around the $\mathrm{T}$ or L-type groynes are experimentally revealed comparing with the experimental results of I-type groynes. Experiments were conducted in a straight flume with a sand box at middle of the flume to make a movable bed. To cover a large measurement area at the downstream of groyne, a long-range laser displacement sensor was used to measure the bed configuration and an optical scale sensor was used to measure the position of laser displacement sensor. The bed levels of downstream area are immediately and accurately measured by the measuring system.

Experimental results show that the maximum scour depth changes greatly with the groyne types and the scour depth for the L-type groyne becomes much smaller than that of I-type groyne. The difference of bed form downstream of the groyne is seen in development and length of sand waves is discussed below.

\section{EXPERIMENTAL SETUP}

Experiments were conducted in a $20 \mathrm{~m}$ long, $50 \mathrm{~cm}$ wide and $50 \mathrm{~cm}$ deep straight flume as shown in Figure 1. In this flume, water discharge and flow depth are controlled by a V-notch weir and a movable gate at the end of flume, respectively. A sand box with a $2 \mathrm{~m}$ long and $10 \mathrm{~cm}$ height is installed at middle of the flume and small sand (mean diameter $d_{m}=0.3 \mathrm{~mm}$ ) is filled up in the box to make a movable bed. A scale groyne models were installed on the sand bed. The sizes and shapes of scale model are indicated in Figure 2 and Table 1. All models were made from vinylchloride plate with $2 \mathrm{~cm}$ thickness. There are two L-type groyne models. One is heading upstream (LU), and the other is heading downstream (LD). Stream-wise lengths $\left(L_{f}\right)$ are $10 \mathrm{~cm}$ for I-type and T-type groyne models, $6 \mathrm{~cm}$ and $10 \mathrm{~cm}$ for L-type groyne models. Span-wise lengths $\left(L_{g}\right)$ are $10 \mathrm{~cm}$ for all cases.

To cover a large measurement area at the downstream of groyne, a long-range laser displacement sensor (KEYENCE LB-300) was used to measure the bed configuration and an optical scale sensor (KEYENCE VP-90) was used to measure 
Table 1. Experimental Conditions

\begin{tabular}{|c|c|c|c|c|c|c|}
\hline Case & I & T & LU6 & LU10 & LD6 & LD10 \\
\hline Type of Groyne Shape & I-type & T-type & LU-type & LU-type & LD-type & LD-type \\
\hline $\begin{array}{c}\text { Stream-wise Length of } \\
\text { groyne model } L_{f}(\mathrm{~cm})\end{array}$ & - & 10 & 6 & 10 & 6 & 10 \\
\hline $\begin{array}{c}\text { Bulk Mean Velocity } v_{0} \\
(\mathrm{~cm} / \mathrm{sec})\end{array}$ & \multicolumn{7}{|c|}{21.0} \\
\hline Flow Depth $(\mathrm{cm})$ & \multicolumn{7}{c|}{10.0} \\
\hline Flow Condition & Emerged \\
\hline
\end{tabular}

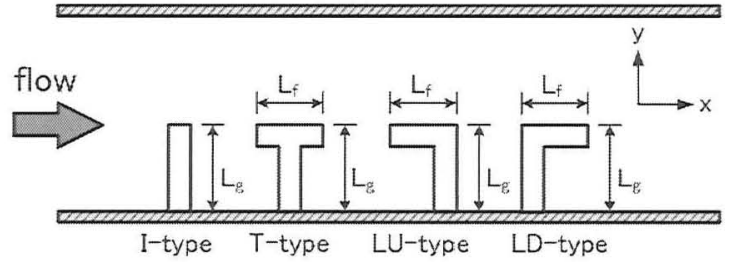

Figure 2 Shapes of Groyne Model

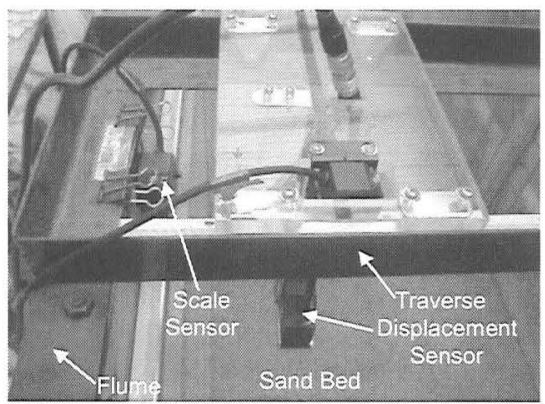

Figure 3. Displacement and Scale Sensors with Traverse

the position ( $\mathrm{x}, \mathrm{y})$ of laser displacement sensor as shown in Figure 3. The bed levels of downstream area are immediately and accurately measured by means of this measuring system.

The hydraulic conditions are shown in Table 1. All experimental cases are under non-submerged condition and the water depth $(h)$ is $10 \mathrm{~cm}$. As seen in Table 1 , each case is called such as T-type (T), L-type heading upstream with $10 \mathrm{~cm}$ length (LU10), L-type heading downstream with $6 \mathrm{~cm}$ length (LD6) and so on. A constant bulk mean (inflow) velocity is applied as $v=21 \mathrm{~cm} / \mathrm{sec}$ for all experimental cases. These experiments are conducted under clear water scour condition without any sand supply from inlet at upstream end. The experiments start from flat bed condition and bed configuration was measured after $60 \mathrm{~min}$ because the scour depth around the tip of I-type groyne becomes stable condition after $60 \mathrm{~min}$ as shown in Figure 4. 


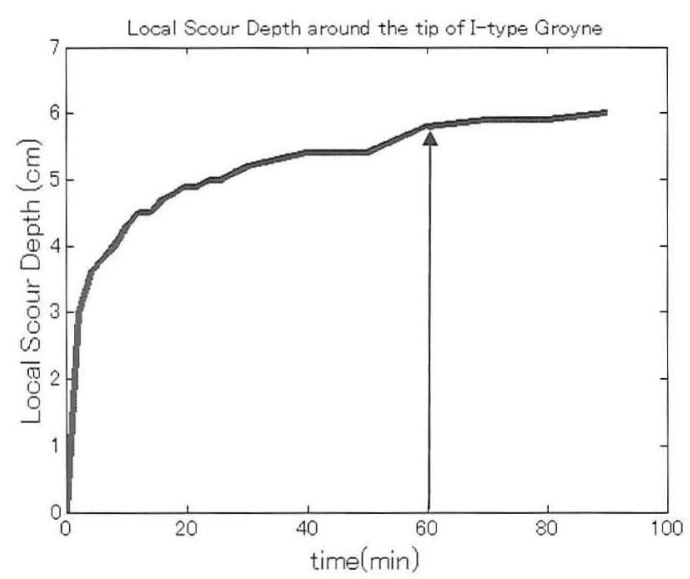

Figure 4. Time variation of local scour depth around the tip of I-type groyne

\section{RESULTS AND DISCUSSION}

Local scour process around groyne tip. Local scouring obviously occurs at the upstream of groyne tip due to vertically-downstream flow. Figure 5 shows the bed configurations after $60 \mathrm{~min}$ around the all types of groyne. In addition, Figure 6 shows the relationship between maximum scour depth and groyne shape.

Comparing with scour depths of all cases, the maximum scour depth is the smallest around L-type groyne heading upstream with $10 \mathrm{~cm}$ stream-wise length (case LU10). On the other hand, the maximum scour depths for the other cases become larger than that of I-type groyne. It can be considered that the maximum depth becomes smaller in proportion to area of dead zone at upstream side of groyne. These phenomena seem to be related with vertically-downstream flow at upstream side of groyne which is smaller than that of I-type groyne. In other words, it means the shear stresses between the two zones become smaller in LU10 case._As a result, amount of suspended sediment from the dead zones decreases.

On the other hand, the scour depths of cases (T, LD6 and LD10) are showing the almost same level whereas the scour depth around L-type groyne is smaller in longer case (LU10) as seen in Figure 6. It can be seen from Figure 5 that area of scour hole is related with scour depth and expand forming concentric circle.

Morphological changes downstream side of groyne. In the downstream area behind groynes, suspended sediment is transport from scouring hole and then local deposition area is formed. Afterward, local scouring is formed behind the local 

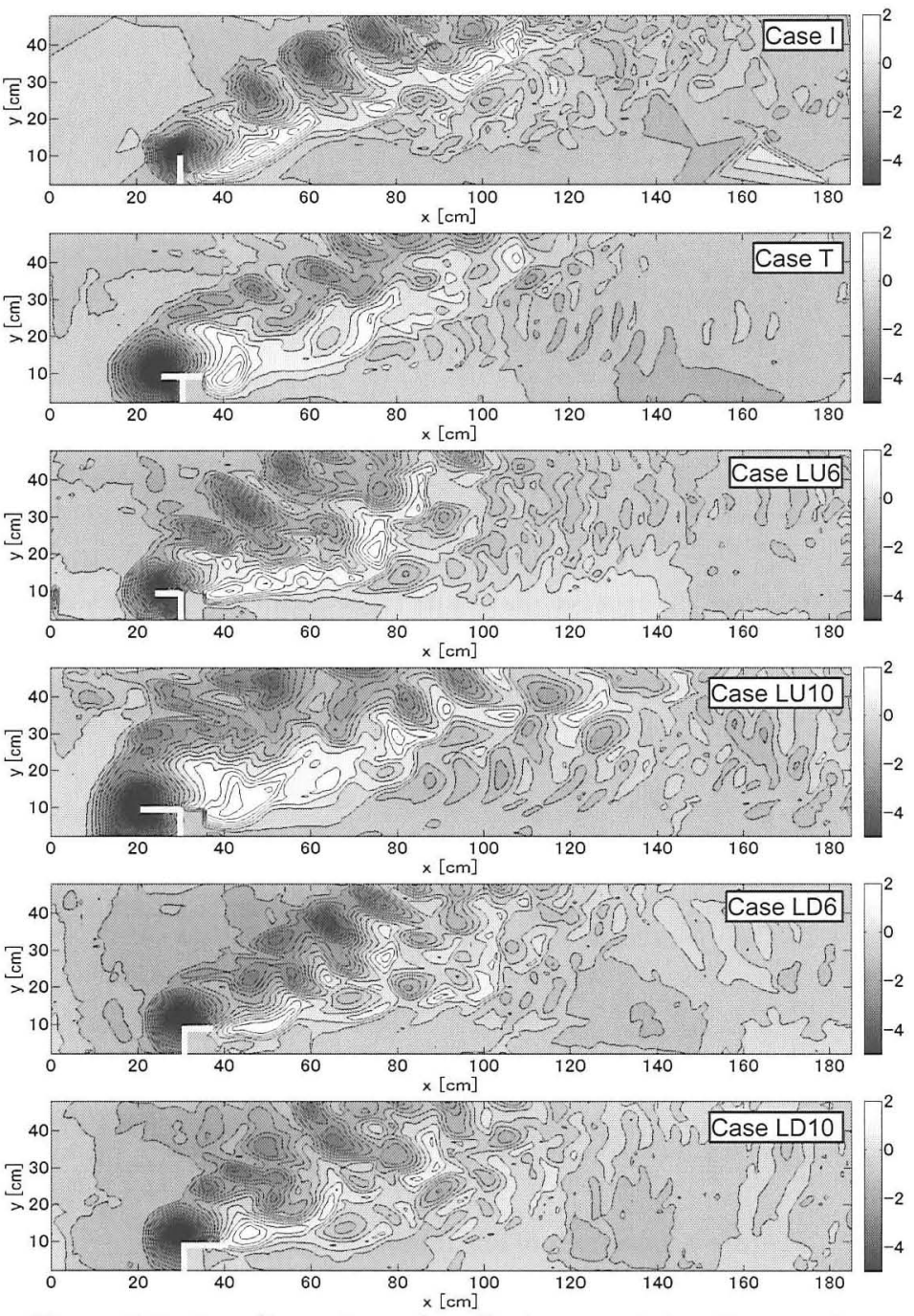

Figure 5. Bed configurations after $60 \mathrm{~min}$ around the all types of groyne

deposition area successively then a sand wave is formed. Figure 7 shows the locations of maximum local deposition estimated from each sand waves as seen in Figure 5.

Comparing with T and L groyne-type cases (T, LU6, LU10, LD6 and LD10), the maximum local deposition of case LD6 is located with some distance downstream from the groyne whereas it located near the groyne tip for the other cases. In addition, 


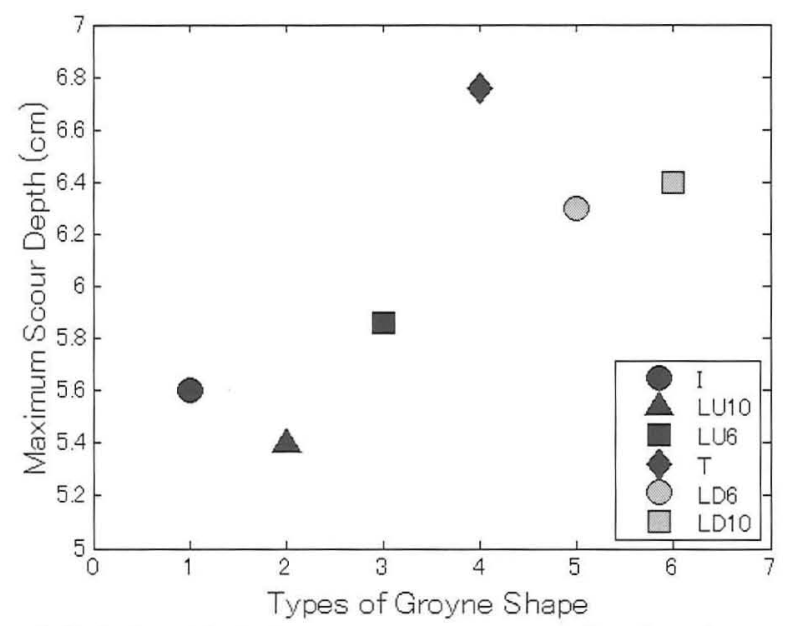

Figure 6. Relationship between maximum scour depth and groyne shape

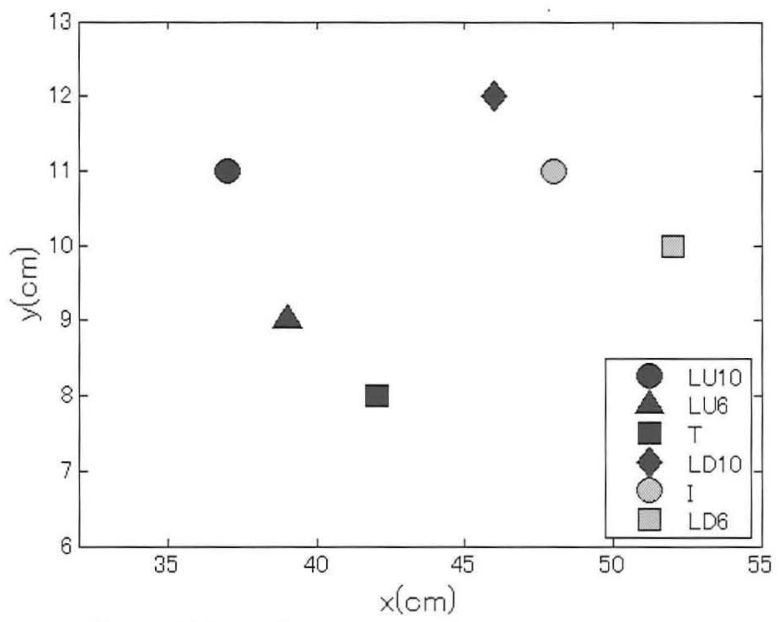

Figure 7. Locations of maximum local deposition

the bed configuration in this case is similar to that of I-type groyne. As for the case LD10, the maximum deposition occurs at the downstream end of the groyne and distributed with belt-shaped deposition. In the cases of T, LU6 and LU10, significant deposition is seen in cross-wise direction and is distributed surrounding scour hole.

Figure 8 shows average wave length $\left(L_{e}\right)$ and average wave height $\left(H_{e}\right)$ for all cases. According to results from Ashida \& Michiue (1972) for criterion of sand wave configuration, the wave length and height of present cases are estimated as $10.62<$ $L_{e}<14.70,1.51<H_{e}<2.79$. As the result, the bed configurations of Figure 5 belong to 


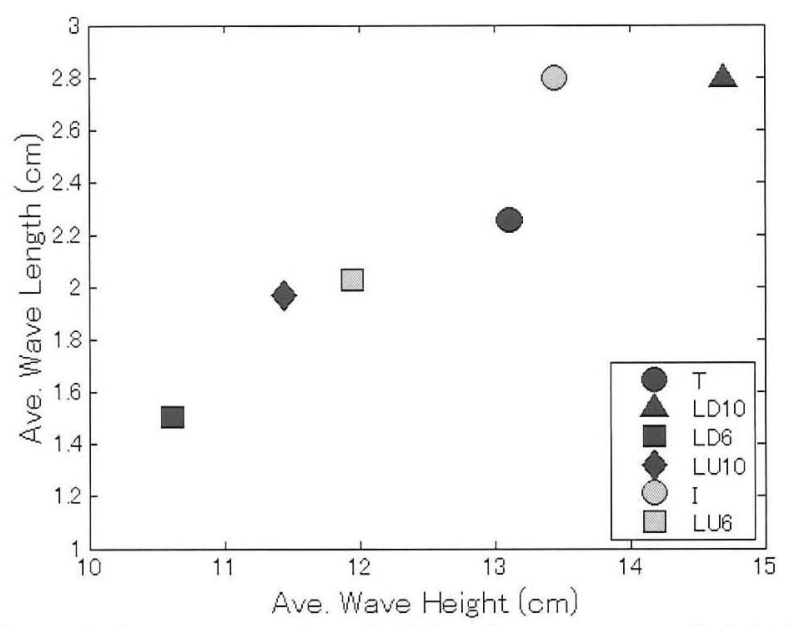

Figure 8. Average wave length $\left(L_{e}\right)$ and average wave height $\left(H_{e}\right)$

lower flow regime and are ripples or dunes. Figure 9 shows the direction of development of sand wave. The sand wave of case T, LU6 and LU10 develop to the opposite wall side whereas the sand wave of case I and LD6 develop to the same direction.

As the result, the location of local deposition is affected by the location of local scour. In case that the local scour occurs at upstream-side of groyne, the deposition forms surrounding the scouring area. On the other hand, in case that local scour occurs at downstream side of groyne, the deposition forms with some distance from the groyne. As seen in Figures 6 and 8, wave length and wave height become smaller as the maximum scour depth is larger, and the opposite property is also seen. It is considered that such tendency is related with location of local deposition. Because the deposition located at downstream in case I, LD6 and LD10, suspended sediment is floating for a long time and deposits on far area from groyne then the wave length and wave height become larger. Also, the direction of sand-wave development shows similar relation. In case that deposition area located at upstream side such as case T, LU6 and LU10, sand-wave develops to direction to the opposite wall side comparing with case I.

\section{CONCLUSION}

In the present study, the characteristics of local scour and bed configuration downstream of several types of groyne are experimentally discussed. As a result, the scour depth becomes large for L-type groyne heading downstream and local deposition occurs with some distance from the groyne. In case of L-type groyne heading upstream, the local scour becomes smaller. However, wave length and wave height becomes larger and sand wave develops to opposite wall side. 


\section{REFERENCES}

Garde, R.J., Subramanya, K. and Namburdripad, K.D. (1961): Study of scour around spur dikes, "Journal of Hydraulic Division", ASCE 87(HY6), 23-37.

Gill, M.A. (1972): Erosion of sand beds around spur-dikes, "Journal of Hydraulic Division", ASCE 98(HY9), 1587-1602.

Kuhnle, R.A., Alonso, C.V., Shields, F.D. (2002): Local scour associated with angled spur dikes, "Journal of Hydraulic. Engineering", ASCE 128(12), 1087-1093. 